\section{Journal of Polytechnic POLITEKNK DERGISI}

\section{POLITEKNIK DERGISI}

JOURNAL Of POLYTECHNIC

\title{
Okul yeri seçiminde coğrafi bilgi sistemine dayalı AHP-TOPSIS yaklaşımı: Ankara ili örneği
}

Geographic information system-based AHPTOPSIS approach for school site selection: $A$ case study for Ankara

Yazar(lar) (Author(s)): Ayșenur USLU, Kübra KIZILOĞLU, Selçuk Kürșat işLEYEN, Erkay KAHYA

Bu makaleye șu șekilde atıfta bulunabilirsiniz (To cite to this article): Uslu A., Kızıloğlu K., İşleyen S. K. ve Kahya E., "Okul yeri seçiminde coğrafi bilgi sistemine dayalı AHP-TOPSIS yaklașımı: Ankara ili örneği”, Politeknik Dergisi, 20(4): 933-943, (2017).

Erișim linki (To link to this article): http://dergipark.gov.tr/politeknik/archive DOI: 10.2339/politeknik.369099 


\title{
Okul Yeri Seçiminde Coğrafi Bilgi Sistemine Dayalı AHP-TOPSIS Yaklaşımı: Ankara İli Örneği
}

\author{
Araştırma Makalesi / Research Article \\ Ayşenur USLU1 ${ }^{1}$, Kübra KIZILOĞLU ${ }^{2}$, Selçuk Kürşat İ̧SEYEN ${ }^{2}$, Erkay KAHYA ${ }^{3}$ \\ ${ }^{1}$ Başkent Üniversitesi, Mühendislik Fakültesi, Endüstri Mühendisliği Bölümü,06810,Ankara \\ ${ }^{2}$ Gazi Üniversitesi, Mühendislik Fakültesi, Endüstri Mühendisliği Bölümü,06570,Ankara \\ ${ }^{3}$ Türksat A.Ş, Konya yolu 40.km, Gölbaşı, 06830,Ankara \\ (Geliş/Received : 10.10.2016 ; Kabul/Accepted : 09.11.2016)
}

\begin{abstract}
öz
Okul yer seçimi problemi, bölgenin nüfus yoğunluğu, ulaşım imkânları, nüfusun kapsanma düzeyi, bölgenin güvenliği gibi birçok kriterin birlikte değerlendirilmesini gerektiren çok kriterli bir karar verme problemidir. Karar verme aşamasında dikkate alınması gereken önemli noktalardan birisi de mevcut yasal kısıtlamalardır. Bu çalışmada, açılması planlanan bir ilköğretim okulu için en uygun yerin belirlenmesi amacıyla Coğrafi Bilgi Sistemine (CBS) dayalı Analitik Hiyerarşi Süreci (AHP) ve İdeal Çözüme Benzerliğine Göre Tercih Sıralama Tekniği (TOPSIS) yöntemlerini içeren yeni bir çözüm yaklaşımı önerilmiştir. İlk olarak imar planı doğrultusunda okul açılabilecek devlet arazileri aday yerler olarak alınmıştır. Bu aday yerlerden yasal kısıtlamalara uyan ve mevcut okullarla birlikte belirlenen yürüme mesafesi içerisinde öğrencileri kapsayan araziler alternatif yerler olarak ArcGIS ESRI programı kullanılarak belirlenmiştir. Daha sonra, literatür incelemesi sonucunda belirlenen kriterlere ait kriter ağırlıkları AHP yöntemi ile hesaplanmış ve alternatif yerler bu ağırlıklar kullanılarak TOPSIS yöntemi ile sıralanmıştır. Önerilen yaklaşım Ankara ili Çankaya ilçesinde uygulanmış ve sonuçlar verilmiştir.
\end{abstract}

Anahtar Kelimeler: CBS, AHP, TOPSIS, tesis yer seçimi, okul yer seçimi.

\section{Geographic Information System-Based AHP-TOPSIS Approach for School Site Selection: A Case Study for Ankara}

\begin{abstract}
Identification of school zones is a multi-criteria decision-making problem, which requires a collective evaluation of many criteria, including population density, transportation facilities, level of the population covered, safety of the region. One of the important points that need to be considered during the decision-making phase is the legal restrictions. In this study, a new solution approach is suggested that uses Analytic Hierarchy Process (AHP) and Technique for Order Preference by Similarity to Ideal Solution (TOPSIS) methods based on Geographical Information System (GIS) for identification of the most convenient location for a primary school to be opened. First, state lands that can accommodate a school in accordance with the development plan have been identified as candidate locations. Among these candidate locations, lands that comply with legal restrictions and cover students within given walking distances with other existing schools were identified as alternative locations by using ArcGIS ESRI software. Then, weights of criteria that were determined by literature reviews were calculated with AHP and alternative locations were ranked with TOPSIS method by using these weights. Suggested approach has been applied to Çankaya district of Ankara city, and results have been presented.
\end{abstract}

Keywords: GIS, AHP, TOPSIS, site selection, school site selection.

\section{GIRIŞ (INTRODUCTION)}

Bir ülkenin ilerlemesi ve kalkınması ancak eğitim ile mümkündür. Eğitim kalitesinin arttırılabilmesi için eğitim sürecine katkı sağlayan tüm unsurların (eğitim programı, öğretmen, öğretme metotları, teknoloji, donanım ve fiziki özellikler, kullanılan materyaller vb.) nitelikli hale getirilmesi ve sürecin etkin bir şekilde planlanması gerekir. Eğitim sürecinin planlanmasında verilmesi gereken

*Sorumlu Yazar (Corresponding Author)

e-posta : aysenur@baskent.edu.tr stratejik kararlardan birisi de okulun kurulacağ yerin belirlenmesidir. Okulların bulunduğu yerler, öğrencilerin okula rahat erişimi, güvenli ve huzurlu bir ortamda bulunmaları gibi birçok açıdan önem taşımakta ve eğitimin kalitesini doğrudan etkilemektedir. Okul yer seçimi problemi; bölgenin nüfus yoğunluğu, ulaşım imkânları, nüfusun kapsanma düzeyi, bölgenin güvenliği, potansiyel nüfus artışı, çevre kirliliği, altyapı imkânları gibi birçok kriterin birlikte değerlendirilmesini gerektiren çok kriterli bir karar verme problemidir. Karar verme aşamasinda dikkate alınması gereken önemli noktalardan birisi de umuma açık ve içkili yerler ile okul binaları arasındaki 
mesafelerin düzenlenmesi gibi yasal kısıtlamalardır. Ayrıca, tüm öğrencilerin belirli bir mesafe ile kapsanabilmesi de önemli bir diğer noktadır. Bu çalışmada, okul açılacak en uygun yerin belirlenmesi amacıyla CBS, AHP ve TOPSIS yöntemlerini içeren bütünleşik bir çözüm yaklaşımı önerilmiştir.

CBS, belli bir amaca yönelik olarak yeryüzüne ait gerçek verilerin toplanmas1, depolanmas1, sorgulanmas1, transferi ve görüntülenmesi işlevlerini yerine getiren araçların tümüdür[1]. CBS'nin kullanım amaçlarından birisi de karar verme aşamasında kullanılacak oldukça fazla miktar ve çeşitteki coğrafi verinin analiz edilerek karar vericiler için doğru girdilerin oluşturulmasıdır. Çalışmada önerilen yaklaşımda, alternatif yerlerin belirlenmesi sürecinde CBS kullanılmıştır. Burada ilk olarak seçim yapılacak bölge için ArcGIS ESRI programında katmanlar (yol, bina, mahalle, çevresel etmenler vb.) oluşturulmuştur. İmar planı doğrultusunda okul açılabilecek devlet arazileri aday yerler olarak alınmıştır. Oluşturulan veriler analiz edilerek bu aday yerlerden yasal kisitlamalara uyan ve mevcut okullarla birlikte maksimum $1500 \mathrm{~m}$. ile ilköğretim düzeyindeki tüm öğrencileri kapsayabilen araziler alternatif yerler olarak ArcGIS ESRI programı kullanılarak belirlenmiştir. CBS'nin karar verme yöntemleriyle birlikte kullanılması girdi kalitesini arttıracağından verilen kararların niteliğini olumlu yönde etkileyecektir.

AHP, 1997 yılında Thomas L. Saaty tarafından geliştirilen ve bir karar problemindeki sonlu sayıdaki alternatifleri birden fazla kritere göre değerlendirerek, önem düzeylerine göre sıralayan çok kriterli bir karar verme yöntemidir. TOPSIS ise 1981 yılında Hwang ve Yoon tarafından geliştirilmiştir. Yöntemin temel amacı pozitif ideal çözüme en yakın, negatif ideal çözüme ise en uzak uzlaşık çözümün bulunmasıdır. Önerilen yaklaşımda alternatif yerlerin CBS ile belirlenmesinden sonra kriter ağırlıkları AHP ile hesaplanmış ve bu ağırlıklar kullanılarak alternatif yerler TOPSIS yöntemi ile sıralanmıştır. AHP ve TOPSIS yöntemlerinin birlikte kullanılması ile AHP'nin kriter ağırlıklarını belirlemedeki üstünlügüünün ve TOPSIS yönteminin alternatifleri hızlı, kolay bir şekilde sıralayabilme özelliklerinden faydalanılması hedeflenmiştir. Daha sonra problem için önerilen yaklaşım
Ankara ili Çankaya ilçesinde uygulanmış ve sonuçlar verilmiştir.

Çalışmanın ikinci bölümünde yer seçimi problemlerinde CBS ve çok kriterli karar verme (ÇKKV) yöntemlerinin birlikte kullanıldığı bazı çalışmalar incelenmiştir. Üçüncü bölümde önerilen yaklaşım açıklanmıştır. Dördüncü bölümde uygulama sonuçları verilmiş, son olarak beşinci bölümde ise çalışmanın sonuçları değerlendirilmiş ve konuya ilişkin gelecekte yapılabilecek çalışmalara değinilmiştir.

\section{LITERATÜR İNCELEMESİ (LITERATURE REVIEW)}

Tesisler için en uygun yerlerin ve bu yerlerden hangi müşterilere hizmet verileceğinin belirlenmesi problemi literatürde yer belirleme-tahsis (location-allocation) problemleri olarak bilinmekte ve genel olarak kamusal yerleşim problemleri (public location problem) ve özel yerleşim problemleri (private location problem) olarak sınıflandırılmaktadır. Özel yerleşim problemlerinde (perakende mağaza, fabrika yeri vb.) maliyetin en küçüklenmesi önemliyken kamusal yerleşim problemlerinde (itfaiye, hastane, okul vb.) nüfusun tesise erişebilirliğini sağlamak önem kazanmaktadır [2]. Okul yer seçimi problemi de literatürde genellikle kamusal yerleşim problemleri sınıfına girmekte ve öncelikle nüfusun kapsanması önemli hâle gelmektedir. 50 yılı aşkın bir süredir araştırmacıların ilgisini çeken kuruluş yeri seçimi ile ilgili literatürdeki matematiksel modeller için Narula [3], Daskin [4], Owen ve Daskin [5], Arabani ve Farahani [6]'nin çalışmaları incelenebilir. Matematiksel modellerin yanı sıra birçok kriteri aynı anda değerlendiren ve karar vericilerin değerlendirmelerini de dikkate alan ÇKKV yöntemleri de kuruluş yerinin belirlenmesinde sıklıkla kullanılmaktadır. Ayrıca, son yıllarda bilgi teknolojilerindeki gelişmelerle birlikte CBS de kuruluş yeri seçiminde kullanılan önemli bir araç haline gelmiştir. Kuruluş yeri seçiminde CBS ve ÇKKV yöntemlerinin birlikte kullanıldığı çalışmaların kısa bir özeti Çizelge 1'de verilmiştir.

Çizelge 1'de verilen çalışmalarda kriter ağırlıkları AHP ile hesaplanmış ve bunlar CBS'de uygunluk haritası çı-

Çizelge 1. Yer seçiminde CBS ve ÇKKV yöntemlerinin kullanıldığı çalışmaların kısa bir özeti (Summary of GIS and MCDM approaches used in site selection)

\begin{tabular}{lcc}
\hline Yazar(lar) & Yöntem & Uygulama Alanı \\
\hline Önüt ve Soner[7] & CBS-AHP-FTOPSIS & Katı atık aktarma yeri seçimi, İstanbul \\
Vahidnia vd.[8] & CBS-FAHP & Hastane yeri seçimi, Tahran \\
Lai vd.[9] & CBS-AHP & İtfaiye yeri seçimi, Çin \\
Roig-Tierno vd.[10] & CBS-AHP & Süpermarket yeri seçimi, İspanya \\
Uyan[11] & CBS-AHP & Güneş tarlasi yeri seçimi, Konya \\
Sánchez-Lozanoa vd.[12] & CBS-AHP-TOPSIS & Güneş tarlasi yeri seçimi, İspanya \\
Mishra vd.[13] & CBS-AHP & Organik çiftlik yeri seçimi, Uttarakhand \\
Rasli vd.[14] & CBS-AHP & Park yeri seçimi, Malezya \\
Çetinkaya vd.[15] & CBS-FAHP-TOPSIS & Mülteci kamp yeri seçimi, Türkiye \\
Chaudhary vd.[16] & CBS-AHP & İtfaiye yeri seçimi, Nepal \\
\hline
\end{tabular}

FAHP: Bulanık AHP, FTOPSIS: Bulanık TOPSIS 
karılması için bir girdi oluşturmuştur. Bu çalışmada önerilen yaklaşımda ise CBS'den elde edilen veriler AHPTOPSIS için girdi oluşturmaktadır. içerisinde öğrencileri kapsayan alanlar seçilmiştir. İkinci aşamayı AHP yönteminin adımları oluşturmaktadır. Burada kriter ağırlıkları belirlenmektedir. Son aşamada

Çizelge 2. Önerilen kriterlerin literatürdeki bazı çalışmalar ile ilişkisi (Relationship of suggested criteria with some studies in the literature)

\begin{tabular}{|c|c|c|c|c|c|c|c|c|c|c|c|c|c|}
\hline \multirow{2}{*}{ Yazar(lar) } & \multicolumn{13}{|c|}{ Kriter No } \\
\hline & 1 & 2 & 3 & 4 & 5 & 6 & 7 & 8 & 9 & 10 & 11 & 12 & 13 \\
\hline Önüt ve Soner[7] & & $\mathrm{X}$ & & & & & & $\mathrm{X}$ & & & & & $\mathrm{X}$ \\
\hline Vahidnia vd.[8] & & & & $\mathrm{X}$ & & $\mathrm{X}$ & & $\mathrm{X}$ & & & $\mathrm{X}$ & & $\mathrm{X}$ \\
\hline Lai vd.[9] & & & & $\mathrm{X}$ & & & $\mathrm{X}$ & $\mathrm{X}$ & & & & & \\
\hline Roig-Tierno vd.[10] & & $\mathrm{X}$ & $\mathrm{X}$ & $\mathrm{X}$ & & & $\mathrm{X}$ & & & & $\mathrm{X}$ & & $\mathrm{X}$ \\
\hline Uyan[11] & & $\mathrm{X}$ & & & & & & $\mathrm{X}$ & $\mathrm{X}$ & & $\mathrm{X}$ & & $\mathrm{X}$ \\
\hline Sánchez-Lozanoa vd.[12] & & & & & & & & $\mathrm{X}$ & $\mathrm{X}$ & & & & $\mathrm{X}$ \\
\hline Mishra vd.[13] & $\mathrm{X}$ & & & & & & & $\mathrm{X}$ & $\mathrm{X}$ & & & & $\mathrm{X}$ \\
\hline Rasli vd.[14] & & & & $\mathrm{X}$ & & & & $\mathrm{X}$ & $\mathrm{X}$ & & & & \\
\hline Çetinkaya vd.[15] & $\mathrm{X}$ & & & $\mathrm{X}$ & & & & $\mathrm{X}$ & $\mathrm{X}$ & & & $\mathrm{X}$ & $\mathrm{X}$ \\
\hline Chaudhary vd.[16] & & $\mathrm{X}$ & & $\mathrm{X}$ & & & & $\mathrm{X}$ & & & & & \\
\hline Arslan ve Yıldız [20] & & $\mathrm{X}$ & & $\mathrm{X}$ & & & & & & $\mathrm{X}$ & & & $\mathrm{X}$ \\
\hline Önerilen çalışma & $\mathrm{X}$ & $\mathrm{X}$ & $\mathrm{X}$ & $\mathrm{X}$ & $\mathrm{X}$ & $\mathrm{X}$ & $\mathrm{X}$ & $\mathrm{X}$ & & & & & \\
\hline
\end{tabular}

KriterNo: 1:Altyap1, 2:Erişilebilirlik, 3: Potansiyel büyüme, 4:Nüfus yoğunluğu, 5:Güvenlik, 6:Çevre kirliliği, 7:Çevredeki benzer tesisler, 8:Mesafe (yakınlık/uzaklık), 9:Coğrafi özellikler, 10:Sosyal yap1, 11:Kurulum maliyeti, 12: Risk etmenleri, 13:Diğer

Literatürde okul yeri seçimi konusunu temel alan az sayıda çalışma bulunmaktadır. McNamara [17] çalışmasında eğitimin planlanmasında kullanılan matematiksel modelleri açıklamıştır. Bruno ve Andersen[18], kayıtların azaldığı dönemlerde okulların planlanması için matematiksel bir model önermiştir. Kavili Arap [19] çalışmasında üniversitelerin kuruluş yeri seçiminde dikkate alınan kriterlere değinmiştir. Özdemir ve Tokyay [20] maksimum yürüme mesafesi ve okul kapasitesi kısıtları altında genetik algoritma ve CBS yardımıyla İstanbul, Kadıköy ilçesinde okul yeri seçimi yapmıştır. Arslan ve Yıldız [21] bulanık TOPSIS yöntemi ile Düzce ilinde spor lisesi için yer seçim çalışması yapmışlardır.

ÇKKV yöntemlerini içeren ve yukarıda incelenmiş olan çalışmalarda ele alınan kriterler Çizelge 2'de gösterilmiştir.

Çalışmada ele alınan bölgenin coğrafi özellikleri, risk (deprem, sel vb.) etmenleri ve sosyal yapısı benzer olduğundan bu kriterler dikkate alınmamıştır. Kurulum maliyeti kriteri ise maliyet ikinci planda tutulduğundan ele alınmamıştır. Mesafe kriteri CBS aşamasında kullanılmış ve alternatif yerler ilk 7 kriter ile karar vericinin görüşü alınarak değerlendirilmiştir.

\section{3. ÖNERILEN YÖNTEM (PROPOSED METHOD)}

$\mathrm{Bu}$ çalışmada okul yer seçimi problemi için önerilen yaklaşım 3 aşamadan oluşmaktadır. İlk aşamada alternatif yerler ArcGIS ESRI programı kullanılarak belirlenmektedir. Burada seçilen bölgedeki okul tahsisli alanlar içerisinden, yasal kısıtları sağlayan ve mevcut okullarla birlikte istenilen maksimum yürüme mesafesi ise alternatif yerler, belirlenen kriter ağırlıkları kullanılarak TOPSIS yöntemi ile sıralanmıştır. Önerilen yaklaşımın işleyişi Şekil 1'de şematik olarak gösterilmiştir.

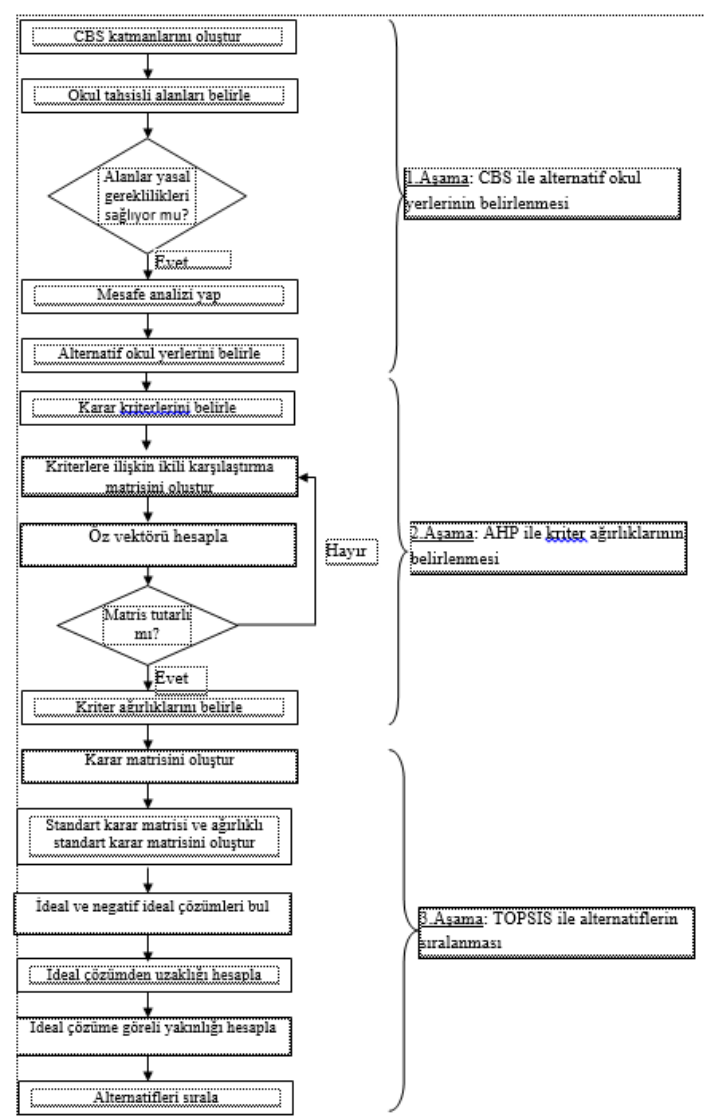

Şekil 1. Önerilen yaklaşımın ișleyiși (Flow chart of the proposed approach) 


\subsection{CBS ile Alternatif Yerlerin Belirlenmesi}

(Determination of Alternative Sites with GIS)

AHP-TOPSIS aşamalarında girdi olarak kullanılacak olan alternatif yerler ArcGIS ESRI paket programı kullanilarak belirlenir.

Adım 1: CBS katmanlarının oluşturulması

İlk olarak CBS katmanları oluşturularak veriler hazırlanır. Şekil 2'de gösterildiği gibi bu çalışmada binalar, yollar, tahsisli alanlar ve mahalle katmanları oluşturulmuştur. Bölgedeki içkili alan, ganyan bayii, gece kulübü, kıraathane, meyhane, tekel bayi, internet kafe gibi umuma açık ve içkili yerler işaretlenerek analizler için bir veri tabanı oluşturulur.

Adım2: Okul tahsisli alanların belirlenmesi ve yasal gerekliliklerin kontrolü

Tahsisli alanlar, imar planında okul yeri olarak belirlenmiş yerleri göstermektedir. İlköğretim ve eğitim kanunumuzun 61. maddesine göre meyhane, kahvehane, kıraathane, bar, elektronik oyun merkezleri gibi umuma açık yerler ile açık alkollü içki satılan yerlerin, okul binalarından kapıdan kapıya en az 100 metre uzaklıkta bulunması zorunludur[22]. Tahsisli alanlar ile yasada adı geçen yerler arasındaki uzaklıklar hesaplanarak 100 metreden yakın mesafede olan tahsisli alanlar değerlendirmeden çıkarılır.

Adım3: Mesafe analizinin yapılması ve alternatif okul yerlerinin belirlenmesi

Yasal gereklilikleri sağlayan tahsisli alanlar ve mevcut okullar birlikte dikkate alınarak mesafe analizi yapılır ve açılacak eğitim kurumları ile tüm öğrencilerin belirlenen mesafe ile kapsanması amaçlanır. Çalışmada bu mesafe ilköğretim öğrencileri düşünülerek $1500 \mathrm{~m}$. olarak alınmıştır. $1500 \mathrm{~m}$. ile kapsamayı sağlayan tahsisli alanlar alternatif yerler olarak belirlenir.

\subsection{AHP ile Kriter Ağırlıklarının Hesaplanması} (Calculation of Criteria Weights with AHP)

Önerilen yaklaşımın 2. aşaması kriter ağırlıklarının AHP yöntemi ile belirlenmesini içermektedir. AHP yönteminin kriterlerin ağırlıklandırılması için uygulanan adımları aşağıda verilmiştir [23-25].

Adım 1: Karar kriterlerinin belirlenmesi

Alternatiflerin değerlendirilmesinde kullanılacak olan kriterler belirlenir.

Adım 2: İkili karşılaştırma matrisinin oluşturulması

$\mathrm{Bu}$ adımda Cizelge 3 'te verilen değerlendirme skalası kullanılarak kriterler kendi içerisinde kıyaslanır ve ikili karşılaştırma matrisi oluş̧urulur (Eşitlik 1).

n: Kriter sayıs1

$A=\left[\begin{array}{cccc}1 & a_{12} & \ldots & a_{1 n} \\ a_{21} & 1 & \ldots & a_{2 n} \\ \vdots & \vdots & \ddots & \vdots \\ a_{n 1} & a_{n 2} & \ldots & 1\end{array}\right]$

Çizelge 3. AHP değerlendirme skalası (AHP evaluation scale) [26]

\begin{tabular}{|c|c|}
\hline $\begin{array}{c}\text { Önem } \\
\text { değerleri }\end{array}$ & Değer Tanımları \\
\hline 1 & Eşit derecede önemli \\
\hline 3 & Biraz daha fazla önemli \\
\hline 5 & Kuvvetli derecede önemli \\
\hline 7 & Çok kuvvetli derecede önemli \\
\hline 9 & Aşırı derecede önemli \\
\hline $2,4,6,8$ & Ara değerler \\
\hline
\end{tabular}

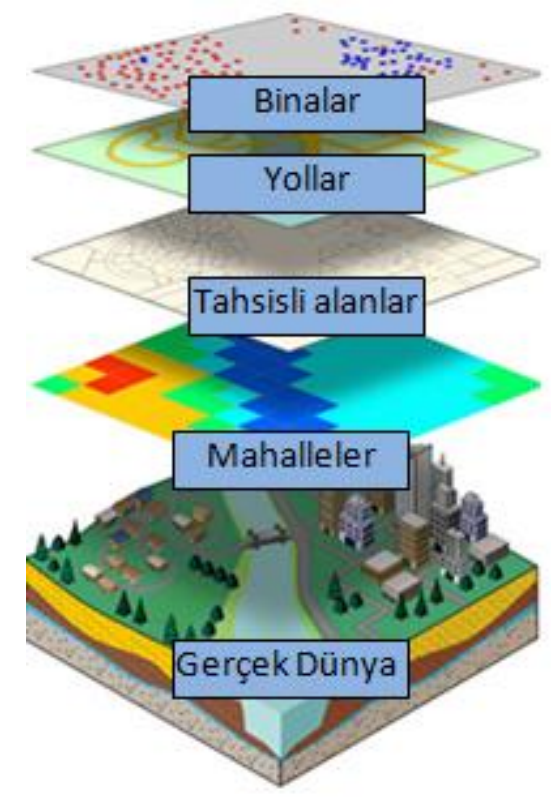

Şekil 2. CBS katmanları (GIS layers)

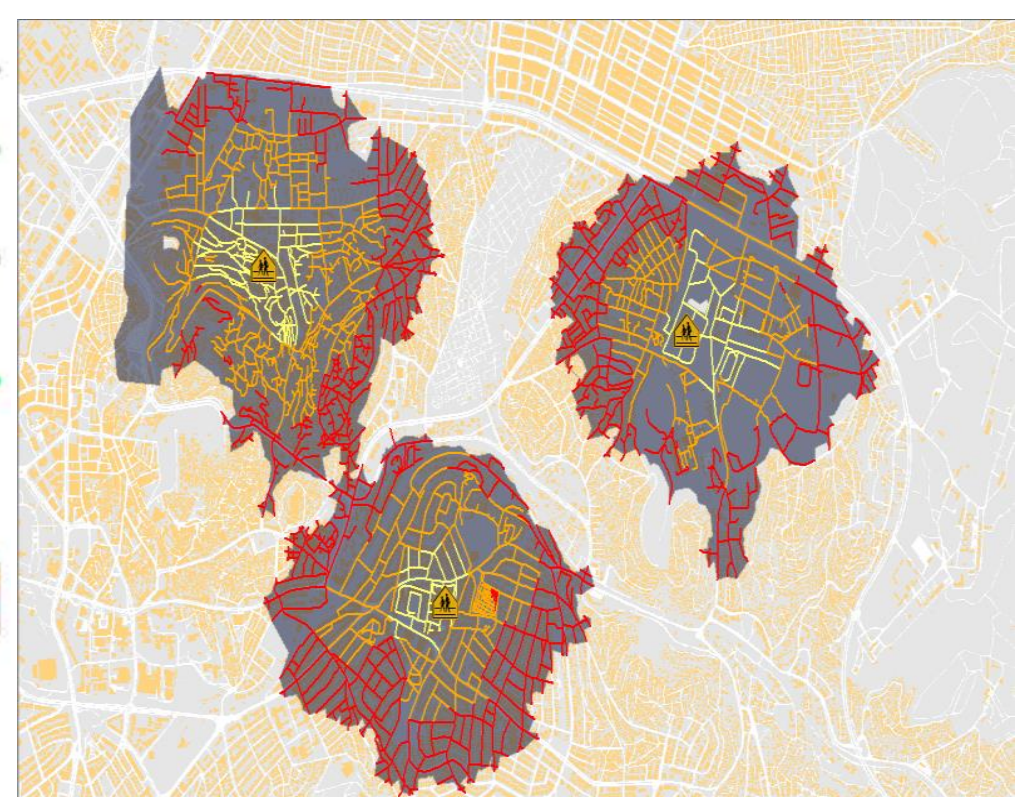

Şekil 3. Mesafe analizi-1500 m. (Distance analysis-1500 m.) 
Adım 3: Öz vektörün (Göreli önem vektörünün) hesaplanmas 1

İkili karşılaştırma matrisindeki her bir faktörün diğer faktörlere göre önemini gösteren öz vektör Eş. 2 ve Eş. 3 kullanılarak hesaplanır.

$\mathrm{i}=1,2, . ., \mathrm{n}$ ve $\mathrm{j}=1,2, \ldots, \mathrm{n}$ olmak üzere;

$b_{i j}=\frac{a_{i j}}{\sum_{i=1}^{n} a_{i j}}$

$w_{i}=\frac{\sum_{j=1}^{n} b_{i j}}{n}$

Kriterlerin yüzde önem düzeylerini belirlemek için W sütun vektörü Eş. 4'te ki şekilde oluşturulur.

$W=\left[\begin{array}{c}w_{1} \\ w_{2} \\ \vdots \\ w_{n}\end{array}\right]$

Adım 4: Tutarlılığın kontrol edilmesi

Adım 2'de oluşturulan ikili karşılaştırma matrisi için tutarlılık oranı (CR) hesaplanır. Bu hesaplama ile yapılan ikili karşılaştırmada karar vericiden kaynaklı bir tutarsızlık olup olmadığı kontrol edilir. Tutarlılık oranının üst limitinin 0.1 olması istenmektedir, 0.1 değerinden büyük olması durumunda yapılan ikili karşılaştırma gözden geçirilerek tekrar değerlendirilir. Tutarlılık oranı Eş. 5 ile hesaplanır. $\mathrm{Bu}$ eşitlikte kullanılan $\lambda$ değeri ikili karşılaştırma matrisinin en büyük özvektör değeri olup Eş.6 ve Eş.7 ile hesaplanır. RI değeri ise kriter sayısına bağlı olarak Çizelge 4'te verilmiştir.

$C R=\frac{\lambda_{\max }-n}{R I(n-1)}$

$\left[d_{i}\right]_{n \times 1}=\left[a_{i j}\right]_{n \times m} \times\left[w_{i}\right]_{n \times 1}$

$\lambda_{\max }=\frac{\sum_{i=1}^{n} d_{i} / w_{i}}{n}$
$\underline{\operatorname{Adım} 2:}$ : Standart karar matrisinin ( R ) ve ağırlıklı standart karar matrisinin (V) oluşturulması

T karar matrisi Eş. 9 kullanılarak normalize edilir ve bu değerler ile standart karar matrisi (R) oluşturulur.

$r_{i j}=\frac{t_{i j}}{\sqrt{\sum_{k=1}^{m} t_{k j}^{2}}}$

$R_{i j}=\left[\begin{array}{cccc}r_{11} & r_{12} & \ldots & r_{1 n} \\ r_{21} & r_{22} & \ldots & r_{2 n} \\ \vdots & \vdots & \ddots & \vdots \\ r_{m 1} & r_{m 2} & \ldots & r_{m n}\end{array}\right]$

Standart karar matrisinin oluşturulmasının ardından AHP'den elde edilen kriter ağırlıkları $\left(w_{i}\right)$ kullanılarak ağırlıklı standart karar matrisi (V) oluşturulur.

$V_{i j}=\left[\begin{array}{cccc}w_{1} r_{11} & w_{2} r_{12} & \ldots & w_{n} r_{1 n} \\ w_{1} r_{21} & w_{2} r_{22} & \ldots & w_{n} r_{2 n} \\ \vdots & \vdots & \ddots & \vdots \\ w_{1} r_{m 1} & w_{2} r_{m 2} & \ldots & w_{n} r_{m n}\end{array}\right]$

Adım 3: İdeal (A*) ve negatif ideal (A) çözümlerin oluşturulması

$\mathrm{V}$ matrisinin sütunlarında yer alan en iyi performans değerleri ideal çözüm kümesini $\left(A^{*}\right)$, en kötü değerler ise negatif ideal çözüm kümesini $\left(\mathrm{A}^{-}\right)$oluşturmaktadır.

$A^{*}=\left\{\left(\max V_{i j} \mid j \in J\right),\left(\left(\min V_{i j}\right) \mid j \in J^{\prime}\right)\right\}$

$A^{-}=\left\{\left(\min V_{i j} \mid j \in J\right),\left(\left(\max V_{i j}\right) \mid j \in J^{\prime}\right)\right\}$

$\mathrm{J}$ fayda yönlü, $J^{\prime}$ maliyet yönlü kriterleri ifade etmektedir. Adım 4: İdeal ve negatif ideal çözümden uzaklığın hesaplanmas 1

Her bir alternatife ilişkin ölçüt değerinin pozitif ideal ve negatif ideal çözüm setinden uzaklıkları belirlenir. Pozitif ideal çözüm setinden uzaklıklar Eş.14, negatif ideal çözüm setinden uzaklıklar Eş. 15 kullanılarak hesaplanır.

Çizelge 4. Rassallık endeksi (RI) verileri (Randomness index) [27]

\begin{tabular}{ccccccccccc}
\hline $\mathbf{n}$ & $\mathbf{1}$ & $\mathbf{2}$ & $\mathbf{3}$ & $\mathbf{4}$ & $\mathbf{5}$ & $\mathbf{6}$ & $\mathbf{7}$ & $\mathbf{8}$ & $\mathbf{9}$ & $\mathbf{1 0}$ \\
\hline $\mathbf{R I}$ & 0 & 0 & 0.58 & 0.9 & 1.12 & 1.24 & 1.32 & 1.41 & 1.45 & 1.49 \\
\hline
\end{tabular}

\subsection{TOPSIS ile Alternatiflerin Sıralanması (Sorting} Alternatives with TOPSIS)

Yaklaşımın 3. aşamasında AHP'den elde edilen kriter ağırlıkları kullanarak alternatiflerin sıralanması için TOPSIS yöntemi kullanılmıştır. Yöntemin işleyişi aşağıda verilmiştir[25][27-28].

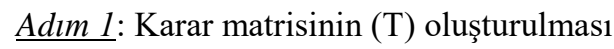

TOPSIS yönteminin ilk adımı alternatiflerin (m), kriterlere (n) göre değerlendirilmesini içeren karar matrisinin oluşturulmasıdır.

$T=\left[\begin{array}{cccc}t_{11} & t_{12} & \ldots & t_{1 n} \\ t_{21} & t_{22} & \ldots & t_{2 n} \\ \vdots & \vdots & \ddots & \vdots \\ t_{m 1} & t_{m 2} & \ldots & t_{m n}\end{array}\right]$

$$
\begin{aligned}
& S_{i}^{*}=\sqrt{\sum_{j=1}^{n}\left(V_{i j}-V_{j}^{*}\right)^{2}} \\
& S_{i}^{-}=\sqrt{\sum_{j=1}^{n}\left(V_{i j}-V_{j}^{-}\right)^{2}}
\end{aligned}
$$

Adım 5: İdeal çözüme göreli yakınlığın $\left(C_{i}^{*}\right)$ hesaplanmas 1

Pozitif ve negatif ideal çözüme olan uzaklıklar kullanılarak her bir alternatifin ideal çözüme olan göreli yakınlığı Eş.16 ile hesaplanır. 


$$
C_{i}^{*}=\frac{S_{i}^{-}}{S_{i}^{-}+S_{i}^{*}}
$$

Burada $0 \leq C_{i}^{*} \leq 1$ aralığında değer alır ve $C_{i}^{*}=1$ alternatifin pozitif ideal çözüm noktasında $C_{i}^{*}=0$ alternatifin negatif ideal çözüm noktasında olduğunu göstermektedir.

Adım 6: Alternatiflerin siralanmas1

Alternatifler ideal çözüme göreli yakınlıklarına göre maksimum $C_{i}^{*}$ değerine sahip alternatif ilk sirada olacak şekilde sıralanır.

\section{UYGULAMA (CASE STUDY)}

$\mathrm{Bu}$ bölümde, önerilen yöntem açılacak bir ilköğretim okuluna en uygun yerin seçilmesi amacıyla Ankara ili Çankaya ilçesinde uygulanmıştır. Bu bölümde ilk olarak çalışmanın yapıldığı bölge tanıtılmış, daha sonra çalışmada önerilen yaklaşım uygulanmıştır.

\section{1. Çalışma Alanı (Study Area)}

Çalışma, Ankara ili Çankaya ilçesinde gerçekleştirilmiştir. İlçe'de 124 mahalle ve 333.547 konut bulunmaktadır. 2015 verilerine göre ilçenin nüfusu 922.536'dır. İlçe sınırları içerisinde 103 ilköğretim okulu, 46 lise, 59 özel okul, 4 devlet üniversitesi, 8 vakıf üniversitesi ile Kara Harp Okulu bulunmaktadır[29].

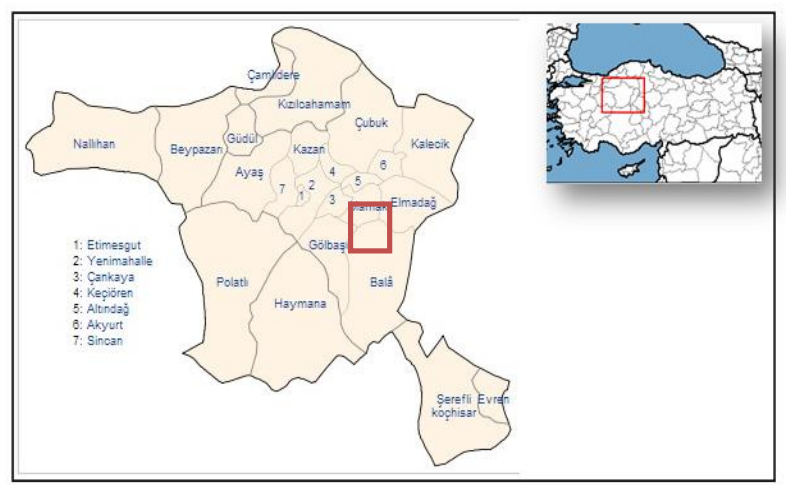

Şekil 4. İlçenin coğrafik konumu (The geographical location of the district)

\subsection{Alternatif Yerlerin Belirlenmesi (Determination of Alternative Sites)}

Adım1: CBS katmanları ve gerekli veriler oluşturulur.

$\mathrm{Bu}$ adımda ilçenin uydu görüntüsü ve gerekli veri katmanları (mahalle, bina, yol, çevresel etmen, okul tahsisli alan) oluşturulmuştur. Mahalle katmanı ilçede bulunan mahalleleri, bina katmanı ise bina verilerini içermektedir. Okul tahsisli alan imar planında okul yeri olarak belirlenmiş boş arsalardır. Yol katmanı ilçedeki yolları göstermektedir. Çevresel etmen katmanında ise bar, ganyan bayi, gazino/gece kulübü, kıraathane, meyhane, tekel bayi, internet kafe vb. veriler tutulmuştur.

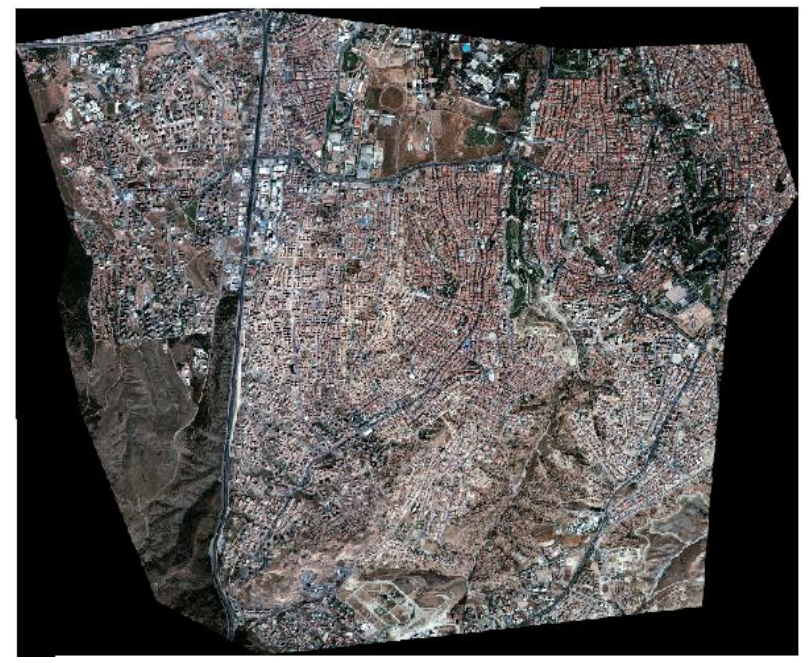

Şekil 5. İlçenin uydu görüntüsü (The satellite image of the district)

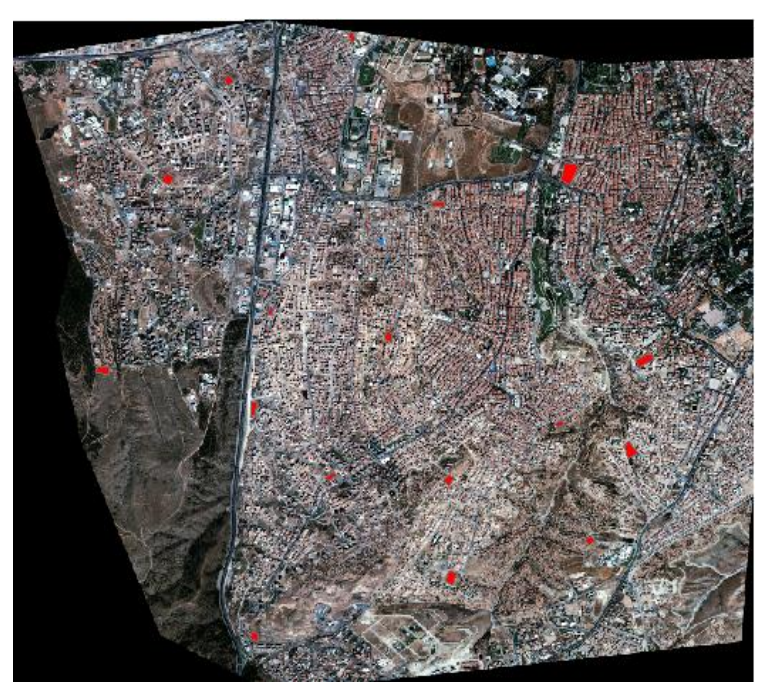

Şekil 6. Okul tahsisli alanlar (The areas allocated for school)

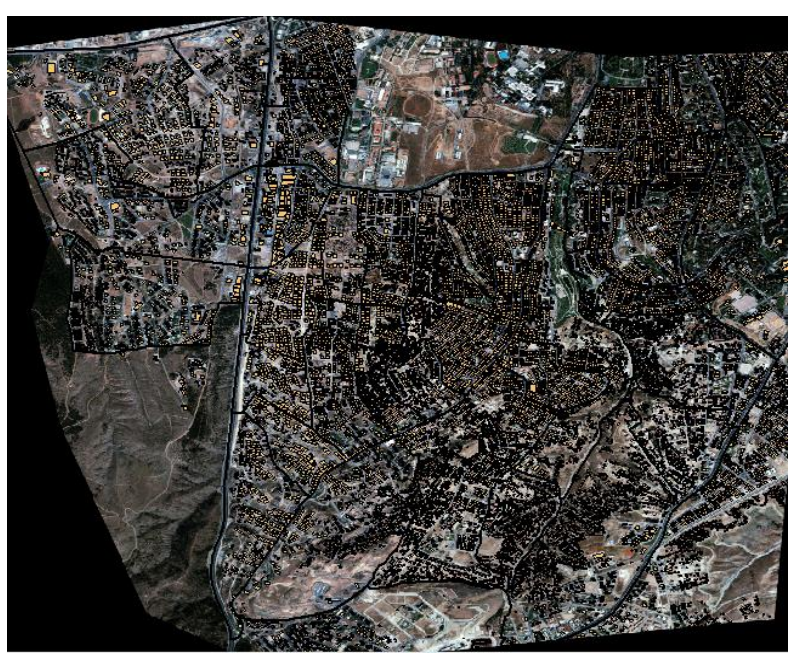

Şekil 7. Mahalle ve bina katmanı (District and building layer) 


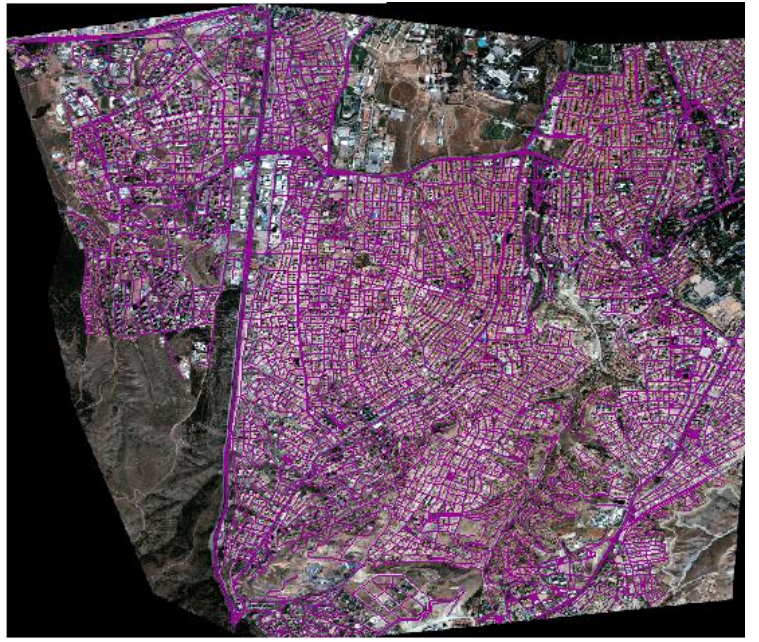

Şekil 8. Yol katmanı (Roads layer)

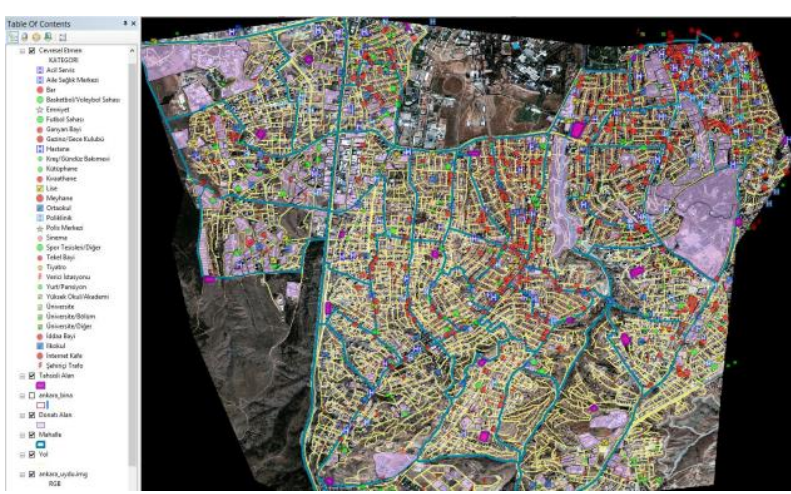

Şekil 9. Çevresel etmenlerin gösterimi (Representation of environmental factors)

Adım 2: Okul tahsisli alanlar belirlenir ve yasal gereklilikler kontrol edilir.

İmar planında okul olarak tahsis edilmiş araziler belirlenir (Şekil 6). Daha sonra bu araziler ile çevresel etmen katmanında tutulan veriler (umuma açık ve içkili yerler) analiz edilerek aralarında 100 m.den fazla uzaklık bulunup bulunmadığı kontrol edilir. 100m'den yakın olan yerler aday yerler arasından çıkarılır.

Adım 3: Mesafe analizi yapılır ve alternatif okul yerleri belirlenir.

Bir ilköğretim öğrencisinin yürüyebileceği maksimum mesafe çalışmada $1500 \mathrm{~m}$. olarak kabul edilmiş ve mevcut okullarla birlikte tüm öğrencileri $1500 \mathrm{~m}$. ile kapsayabilen yerler (Şekil 3) alternatif yerler olarak belirlenmiştir. Çalışmada 17 alternatif yer belirlenmiştir.

\subsection{Kriter Ağırlıklarının Hesaplaması (Calculation of Criteria Weights)}

Adım 1: Karar kriterleri belirlenir.

Yapılan literatür incelemesi sonucunda 7 adet karar kriteri belirlenmiştir. Bunlar; altyap1 $\left(\mathrm{K}_{1}\right)$, erişilebilirlik $\left(\mathrm{K}_{2}\right)$, potansiyel büyüme $\left(\mathrm{K}_{3}\right)$, nüfus $\left(\mathrm{K}_{4}\right)$, güvenlik $\left(\mathrm{K}_{5}\right)$, çevre kirliliği $\left(\mathrm{K}_{6}\right)$ ve çevredeki okul sayısıdır $\left(\mathrm{K}_{7}\right)$. Altyapı kriteri, okul kurulması planlanan yerin elektrik, internet, doğalgaz vb. donanımları içermesini ifade etmektedir. Erişilebilirlik, öğrencilerin okula ulaşabilme kolaylığının değerlendirildiği kriterdir. Potansiyel büyüme, bölgedeki nüfus artış oranını, nüfus ise ilkokula gidecek olan mevcut kişi sayısının değerlendirilmesini içermektedir. Güvenlik, değerlendirilecek yerlerin işlenen suç oranı, meydana gelen trafik kazaları vb. yönünden değerlendirilmesidir. Çevre kirliliği, bölgenin hava ve gürültü kirliliği bakımından incelenmesidir. Çevredeki okul sayısı kriteri ise önceliğin okul sayısı az olan bölgelere verilmesi amacıyla ele alınmıştır. $\mathrm{K}_{6}$ ve $\mathrm{K}_{7}$ kriterleri maliyet yönlü, diğer kriterler ise fayda yönlü kriterlerdir.

Adım 2: İkili karşılaştırma matrisi oluşturulur.

Karar kriterleri uzman görüşü ile değerlendirilerek, kriter ağırlıklarının belirlenmesi amacıyla Çizelge 5'te verilen ikili karşılaştırma matrisi oluşturulmuştur.

Çizelge 5. Kriterlere ilişkin ikili karşılaştırma matrisi (Pairwise comparison matrix on the criteria)

\begin{tabular}{cccccccc}
\hline & $\mathbf{K}_{\mathbf{1}}$ & $\mathbf{K}_{\mathbf{2}}$ & $\mathbf{K}_{\mathbf{3}}$ & $\mathbf{K}_{\mathbf{4}}$ & $\mathbf{K}_{\mathbf{5}}$ & $\mathbf{K}_{\mathbf{6}}$ & $\mathbf{K}_{\mathbf{7}}$ \\
\hline $\mathbf{K}_{\mathbf{1}}$ & 1.0 & 0.2 & 0.5 & 0.14 & 0.33 & 0.33 & 0.5 \\
$\mathbf{K}_{\mathbf{2}}$ & & 1.0 & 5.0 & 0.33 & 2.0 & 3.0 & 4.0 \\
$\mathbf{K}_{\mathbf{3}}$ & & & 1.0 & 0.2 & 0.33 & 0.5 & 1.0 \\
$\mathbf{K}_{\mathbf{4}}$ & & & & 1.0 & 3.0 & 5.0 & 5.0 \\
$\mathbf{K}_{\mathbf{5}}$ & & & & & 1.0 & 2.0 & 0.3 \\
& & & & & & & 3 \\
$\mathbf{K}_{\mathbf{6}}$ & & & & & & 1.0 & 0.3 \\
& & & & & & & 3 \\
$\mathbf{K}_{\mathbf{7}}$ & & & & & & & 1.0 \\
\hline
\end{tabular}

Adım 3: Özvektör hesaplanır.

Çizelge 5'te verilen ikili karşılaştırma matrisindeki her bir kriterin diğer kriterlere göre önemini gösteren özvektör Eş. 17'de verilmiştir.

$W=\left[\begin{array}{l}0.04 \\ 0.22 \\ 0.06 \\ 0.37 \\ 0.11 \\ 0.08 \\ 0.12\end{array}\right]$

Adım 4: Matrisin tutarlılığı kontrol edilir.

Çizelge 5'te verilen matris için $\lambda_{\max }$ değeri 7.64 olarak hesaplanmıştır.

$C I=\frac{7.64-7}{6}=0.1$

$C R=\frac{0.1}{1.32}=0.08$

Bulunan CR oranı 0.1 'den küçük olduğundan, matris tutarlidir.

4.4. Alternatiflerin Siralanması (Sorting Alternatives) Adım 1: Karar matrisi oluşturulur.

Alternatif yerlerin kriterlere göre değerlendirildiği karar matrisi Çizelge 6'da verilmiştir. 
Çizelge 6. Karar matrisi(T) (Decision matrix(T))

\begin{tabular}{llllllll}
\hline & $\mathbf{K}_{\mathbf{1}}$ & $\mathbf{K}_{\mathbf{2}}$ & $\mathbf{K}_{\mathbf{3}}$ & $\mathbf{K}_{\mathbf{4}}$ & $\mathbf{K}_{\mathbf{5}}$ & $\mathbf{K}_{\mathbf{6}}$ & $\mathbf{K}_{\mathbf{7}}$ \\
\hline $\mathbf{A}_{\mathbf{1}}$ & 3.0 & 1.0 & 0.10 & 5000.0 & 3.0 & 3.0 & 3.0 \\
$\mathbf{A}_{\mathbf{2}}$ & 5.0 & 3.0 & 0.03 & 2250.0 & 5.0 & 5.0 & 2.0 \\
$\mathbf{A}_{\mathbf{3}}$ & 3.0 & 3.0 & 0.05 & 3010.0 & 3.0 & 7.0 & 5.0 \\
$\mathbf{A}_{\mathbf{4}}$ & 5.0 & 5.0 & 0.26 & 3542.0 & 3.0 & 3.0 & 2.0 \\
$\mathbf{A}_{\mathbf{5}}$ & 7.0 & 3.0 & 0.24 & 3100.0 & 3.0 & 1.0 & 3.0 \\
$\mathbf{A}_{\mathbf{6}}$ & 1.0 & 3.0 & 0.15 & 2985.0 & 1.0 & 1.0 & 4.0 \\
$\mathbf{A}_{\mathbf{7}}$ & 9.0 & 7.0 & 0.13 & 2850.0 & 5.0 & 1.0 & 1.0 \\
$\mathbf{A}_{\mathbf{8}}$ & 3.0 & 3.0 & 0.31 & 2560.0 & 5.0 & 1.0 & 6.0 \\
$\mathbf{A}_{\mathbf{9}}$ & 5.0 & 5.0 & 0.18 & 4800.0 & 7.0 & 3.0 & 2.0 \\
$\mathbf{A}_{\mathbf{1 0}}$ & 7.0 & 1.0 & 0.23 & 4250.0 & 9.0 & 5.0 & 3.0 \\
$\mathbf{A}_{11}$ & 3.0 & 1.0 & 0.08 & 5100.0 & 3.0 & 5.0 & 4.0 \\
$\mathbf{A}_{12}$ & 3.0 & 5.0 & 0.07 & 5250.0 & 5.0 & 3.0 & 0.0 \\
$\mathbf{A}_{\mathbf{1 3}}$ & 1.0 & 3.0 & 0.12 & 4680.0 & 7.0 & 3.0 & 1.0 \\
$\mathbf{A}_{\mathbf{1 4}}$ & 1.0 & 3.0 & 0.21 & 3900.0 & 1.0 & 1.0 & 2.0 \\
$\mathbf{A}_{\mathbf{1 5}}$ & 3.0 & 7.0 & 0.25 & 2800.0 & 1.0 & 3.0 & 0.0 \\
$\mathbf{A}_{16}$ & 5.0 & 7.0 & 0.30 & 5110.0 & 3.0 & 1.0 & 2.0 \\
$\mathbf{A}_{\mathbf{1 7}}$ & 7.0 & 5.0 & 0.27 & 3680.0 & 5.0 & 3.0 & 3.0 \\
\hline
\end{tabular}

Değerlendirmede K1, K2, K5 ve K6 kriterleri sözel ifadelerle değerlendirilmiş, bu sözel ifadeler Çizelge 7'de verilen skala kullanılarak sayısallaştırılmıştır. K3 kriteri $\%$ potansiyel büyüme oranı, K4 kriteri okulun kapsadı ğ1 alandaki nüfus, K7 kriteri ise çevresindeki okul sayısı ile değerlendirilmiştir.

Çizelge 7. TOPSIS değerlendirme skalası (TOPSIS evaluation scale)

\begin{tabular}{|c|c|}
\hline Skala Değeri & Değer Tanımları \\
\hline 1 & Çok düşük \\
\hline 3 & Düşük \\
\hline 5 & Ortalama \\
\hline 7 & Yüksek \\
\hline 9 & Çok yüksek \\
\hline
\end{tabular}

Adım 2: Standart karar matrisi ve ağırlıklı standart karar matrisi oluşturulur

Standart karar matrisi Çizelge 8'de verilmiştir. AHP'den elde edilen ağırlıklar kullanılarak ağırlıklı standart karar matrisi hesaplanmış ve Çizelge 9'de verilmiştir.

Adım 3: İdeal ve negatif ideal çözümler belirlenir.

Ağırlıklı standart karar matrisindeki en iyi ve en kötü değerler belirlenerek Çizelge 10'da verilen ideal ve negatif ideal çözümler belirlenir.

Çizelge 8. Standart karar matrisi(R) (Standard decision matrix $(\mathrm{R})$ )

\begin{tabular}{llllllll}
\hline & $\mathbf{K}_{\mathbf{1}}$ & $\mathbf{K}_{\mathbf{2}}$ & $\mathbf{K}_{\mathbf{3}}$ & $\mathbf{K}_{\mathbf{4}}$ & $\mathbf{K}_{\mathbf{5}}$ & $\mathbf{K}_{\mathbf{6}}$ & $\mathbf{K}_{\mathbf{7}}$ \\
\hline $\mathbf{A}_{\mathbf{1}}$ & 0.15 & 0.06 & 0.12 & 0.31 & 0.16 & 0.22 & 0.24 \\
$\mathbf{A}_{\mathbf{2}}$ & 0.25 & 0.17 & 0.04 & 0.14 & 0.26 & 0.36 & 0.16 \\
$\mathbf{A}_{\mathbf{3}}$ & 0.15 & 0.17 & 0.06 & 0.19 & 0.16 & 0.50 & 0.41 \\
$\mathbf{A}_{\mathbf{4}}$ & 0.25 & 0.28 & 0.32 & 0.22 & 0.16 & 0.22 & 0.16 \\
$\mathbf{A}_{\mathbf{5}}$ & 0.36 & 0.17 & 0.30 & 0.19 & 0.16 & 0.07 & 0.24 \\
$\mathbf{A}_{\mathbf{6}}$ & 0.05 & 0.17 & 0.19 & 0.18 & 0.05 & 0.07 & 0.33 \\
$\mathbf{A}_{\mathbf{7}}$ & 0.46 & 0.40 & 0.16 & 0.18 & 0.26 & 0.07 & 0.08 \\
$\mathbf{A}_{\mathbf{8}}$ & 0.15 & 0.17 & 0.38 & 0.16 & 0.26 & 0.07 & 0.49 \\
$\mathbf{A}_{\mathbf{9}}$ & 0.25 & 0.28 & 0.22 & 0.30 & 0.37 & 0.22 & 0.16 \\
$\mathbf{A}_{\mathbf{1 0}}$ & 0.36 & 0.06 & 0.28 & 0.26 & 0.47 & 0.36 & 0.24 \\
$\mathbf{A}_{\mathbf{1 1}}$ & 0.15 & 0.06 & 0.10 & 0.31 & 0.16 & 0.36 & 0.33 \\
$\mathbf{A}_{\mathbf{1 2}}$ & 0.15 & 0.28 & 0.09 & 0.32 & 0.26 & 0.22 & 0.00 \\
$\mathbf{A}_{\mathbf{1 3}}$ & 0.05 & 0.17 & 0.15 & 0.29 & 0.37 & 0.22 & 0.08 \\
$\mathbf{A}_{\mathbf{1 4}}$ & 0.05 & 0.17 & 0.26 & 0.24 & 0.05 & 0.07 & 0.16 \\
$\mathbf{A}_{15}$ & 0.15 & 0.40 & 0.31 & 0.17 & 0.05 & 0.22 & 0.00 \\
$\mathbf{A}_{16}$ & 0.25 & 0.40 & 0.37 & 0.31 & 0.16 & 0.07 & 0.16 \\
$\mathbf{A}_{\mathbf{1 7}}$ & 0.36 & 0.28 & 0.33 & 0.23 & 0.26 & 0.22 & 0.24 \\
\hline
\end{tabular}


Çizelge 9. Ağırlıklı standart karar matrisi(V) (Weighted standard decision matrix(V))

\begin{tabular}{llllllll}
\hline & $\mathbf{K}_{\mathbf{1}}$ & $\mathbf{K}_{\mathbf{2}}$ & $\mathbf{K}_{\mathbf{3}}$ & $\mathbf{K}_{\mathbf{4}}$ & $\mathbf{K}_{\mathbf{5}}$ & $\mathbf{K}_{\mathbf{6}}$ & $\mathbf{K}_{\mathbf{7}}$ \\
\hline $\mathbf{A}_{\mathbf{1}}$ & 0.006 & 0.013 & 0.007 & 0.115 & 0.018 & 0.017 & 0.028 \\
$\mathbf{A}_{\mathbf{2}}$ & 0.010 & 0.038 & 0.002 & 0.052 & 0.030 & 0.028 & 0.019 \\
$\mathbf{A}_{\mathbf{3}}$ & 0.006 & 0.038 & 0.004 & 0.069 & 0.018 & 0.039 & 0.047 \\
$\mathbf{A}_{\mathbf{4}}$ & 0.010 & 0.063 & 0.019 & 0.081 & 0.018 & 0.017 & 0.019 \\
$\mathbf{A}_{\mathbf{5}}$ & 0.014 & 0.038 & 0.018 & 0.071 & 0.018 & 0.006 & 0.028 \\
$\mathbf{A}_{6}$ & 0.002 & 0.038 & 0.011 & 0.068 & 0.006 & 0.006 & 0.038 \\
$\mathbf{A}_{7}$ & 0.017 & 0.088 & 0.010 & 0.065 & 0.030 & 0.006 & 0.009 \\
$\mathbf{A}_{\mathbf{8}}$ & 0.006 & 0.038 & 0.023 & 0.059 & 0.030 & 0.006 & 0.056 \\
$\mathbf{A}_{9}$ & 0.010 & 0.063 & 0.013 & 0.110 & 0.042 & 0.017 & 0.019 \\
$\mathbf{A}_{10}$ & 0.014 & 0.013 & 0.017 & 0.097 & 0.054 & 0.028 & 0.028 \\
$\mathbf{A}_{11}$ & 0.006 & 0.013 & 0.006 & 0.117 & 0.018 & 0.028 & 0.038 \\
$\mathbf{A}_{12}$ & 0.006 & 0.063 & 0.005 & 0.120 & 0.030 & 0.017 & 0.000 \\
$\mathbf{A}_{13}$ & 0.002 & 0.038 & 0.009 & 0.107 & 0.042 & 0.017 & 0.009 \\
$\mathbf{A}_{14}$ & 0.002 & 0.038 & 0.015 & 0.089 & 0.006 & 0.006 & 0.019 \\
$\mathbf{A}_{15}$ & 0.006 & 0.088 & 0.018 & 0.064 & 0.006 & 0.017 & 0.000 \\
$\mathbf{A}_{16}$ & 0.010 & 0.088 & 0.022 & 0.117 & 0.018 & 0.006 & 0.019 \\
$\mathbf{A}_{17}$ & 0.014 & 0.063 & 0.020 & 0.084 & 0.030 & 0.017 & 0.028 \\
\hline
\end{tabular}

Çizelge 10. İdeal ve negatif ideal çözümler (Ideal and negative ideal solutions)

\begin{tabular}{llllllll}
\hline A* & $\mathbf{0 . 0 1 7 4}$ & $\mathbf{0 . 0 8 8 5}$ & $\mathbf{0 . 0 2 2 7}$ & $\mathbf{0 . 1 2 0 4}$ & $\mathbf{0 . 0 5 4 1}$ & $\mathbf{0 . 0 0 5 5}$ & $\mathbf{0 . 0 0 0 0}$ \\
\hline A- & 0.0019 & 0.0126 & 0.0022 & 0.0516 & 0.0060 & 0.0387 & 0.0563 \\
\hline
\end{tabular}

Adım 4 ve Adım 5: İdeal ve negatif ideal çözümden uzaklıklar ve ideal çözüme göreli yakınlık hesaplanır.

Alternatiflerin ideal ve negatif ideal çözümden uzaklıkları ve ideal çözüme göreli yakınlık değerleri Eş.[14-16] kullanılarak hesaplanmış ve Çizelge 11'da verilmiştir.

Çizelge 11. İdeal ve negatif ideal çözümden uzaklık ve ideal çözüme göreli yakınlık değerleri (Distance from ideal and negative ideal solutions and relative closeness values)

\begin{tabular}{lccc}
\hline & $\mathbf{S}^{*}$ & $\mathbf{S}^{-}$ & $\mathbf{C}^{*}$ \\
\hline $\mathbf{A}_{1}$ & 0.0915 & 0.0738 & 0.4464 \\
$\mathbf{A}_{2}$ & 0.0959 & 0.0530 & 0.3560 \\
$\mathbf{A}_{3}$ & 0.1015 & 0.0345 & 0.2539 \\
$\mathbf{A}_{4}$ & 0.0634 & 0.0763 & 0.5460 \\
$\mathbf{A}_{5}$ & 0.0844 & 0.0586 & 0.4096 \\
$\mathbf{A}_{6}$ & 0.0967 & 0.0495 & 0.3387 \\
$\mathbf{A}_{7}$ & 0.0622 & 0.1006 & 0.6178 \\
\hline
\end{tabular}

\begin{tabular}{llll}
\hline $\mathbf{A}_{8}$ & 0.1012 & 0.0530 & 0.3436 \\
$\mathbf{A 9}$ & 0.0389 & 0.0967 & 0.7131 \\
$\mathbf{A}_{10}$ & 0.0872 & 0.0754 & 0.4636 \\
$\mathbf{A}_{11}$ & 0.0969 & 0.0701 & 0.4200 \\
$\mathbf{A}_{12}$ & 0.0422 & 0.1075 & 0.7179 \\
$\mathbf{A}_{13}$ & 0.0593 & 0.0882 & 0.5980 \\
$\mathbf{A}_{14}$ & 0.0805 & 0.0690 & 0.4615 \\
$\mathbf{A}_{15}$ & 0.0758 & 0.0992 & 0.5668 \\
$\mathbf{A}_{16}$ & 0.0415 & 0.1147 & 0.7341 \\
$\mathbf{A}_{17}$ & 0.0588 & 0.0770 & 0.5673 \\
\hline
\end{tabular}

Adım 6: Alternatifler siralanır.

Alternatif yerler Çizelge 10 'da verilen C* değerlerine göre sıralandığında, ideal çözüme göreli yakınlığı en yüksek olan 16. alternatif, ilk sırada yer almaktadır (Şekil 10). Diğer alternatiflerin sıralaması ise Çizelge 12 'de görülmektedir.

Çizelge 12. Alternatiflerin sıralanması (Sorting of alternatives)

\begin{tabular}{lccccccccccccccccc}
\hline Siralama & $\mathbf{1}$ & $\mathbf{2}$ & $\mathbf{3}$ & $\mathbf{4}$ & $\mathbf{5}$ & $\mathbf{6}$ & $\mathbf{7}$ & $\mathbf{8}$ & $\mathbf{9}$ & $\mathbf{1 0}$ & $\mathbf{1 1}$ & $\mathbf{1 2}$ & $\mathbf{1 3}$ & $\mathbf{1 4}$ & $\mathbf{1 5}$ & $\mathbf{1 6}$ & $\mathbf{1 7}$ \\
\hline Alternatif & $\mathrm{A}_{16}$ & $\mathrm{~A}_{12}$ & $\mathrm{~A}_{9}$ & $\mathrm{~A}_{7}$ & $\mathrm{~A}_{13}$ & $\mathrm{~A}_{17}$ & $\mathrm{~A}_{15}$ & $\mathrm{~A}_{4}$ & $\mathrm{~A}_{10}$ & $\mathrm{~A}_{14}$ & $\mathrm{~A}_{1}$ & $\mathrm{~A}_{11}$ & $\mathrm{~A}_{5}$ & $\mathrm{~A}_{2}$ & $\mathrm{~A}_{8}$ & $\mathrm{~A}_{6}$ & $\mathrm{~A}_{3}$
\end{tabular}




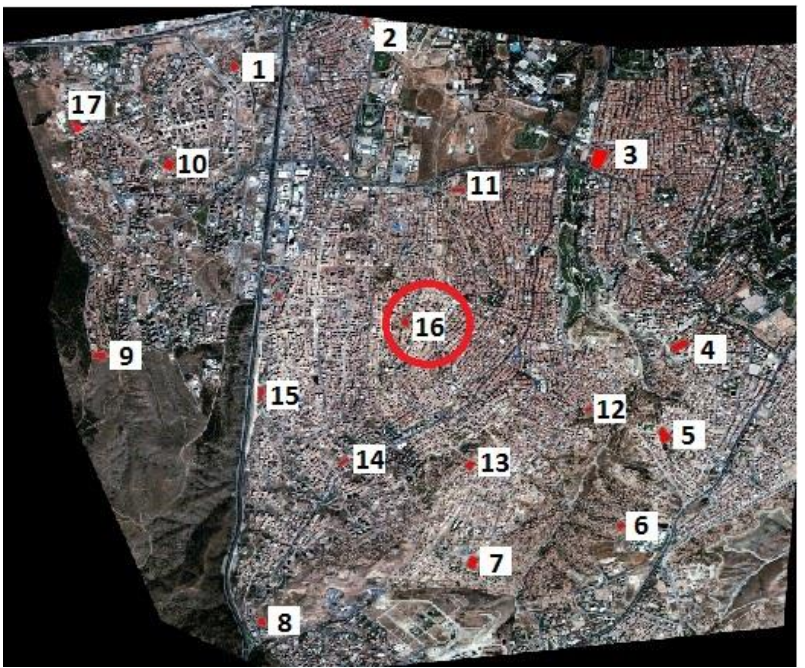

Şekil 10. Alternatiflerin harita üzerinde gösterimi (Representation of alternatives on the map)

\section{SONUÇ VE ÖNERILER (CONCLUSION AND FUTURE DIRECTIONS)}

Bu çalışmada okul yer seçimi problemi için üç aşamadan oluşan yeni bir çözüm yaklaşımı önerilmiştir. Önerilen bütünleşik yaklaşımın ilk aşamasında coğrafi bilgi sistemi yardımıyla okul tahsisli alanlar belirlenip, mesafe analizleri yapılarak alternatif yerler belirlenmiştir. Bu alternatif yerler, imar planında okul yeri olarak tahsis edilmiş, yasal kısıtları sağlayan ve öğrencilerin maksimum yürüme mesafesini belirlenen uzaklık ile sınırlayan yerlerdir. İkinci aşamada literatür araştırması sonucunda belirlenen 7 kriter ( altyapı, erişilebilirlik, potansiyel büyüme, nüfus, güvenlik, çevre kirliliği, çevredeki okul sayısı) AHP yöntemi ile ağırlıklandırılmış, son aşamada ise alternatif yerler, hesaplanan kriter ağırlıkları kullanılarak TOPSIS yöntemi ile sıralanmıştır.

Önerilen yaklaşımda CBS kullanılmasıyla, ÇKKV yöntemleriyle kantitatif olarak hesaplanamayacak olan öğrencilerin kapsanması ve yasal uzaklık kısitlamaları CBS'de yapılan mesafe analizleriyle çözüme yansıtılmıştır. Çankaya ilçesinde açılacak olan bir ilköğretim okulu için yapılan uygulama çalışmasında 17 alternatif yer seçilmiştir. AHP yöntemi ile hesaplanan kriter ağırlıklarına bakıldığında en önemli kriterin nüfus $\left(\mathrm{K}_{4}\right)$ olduğu görülmektedir. Kamusal yerleşim problemlerinde öncelikli hedef nüfusun kapsanmasını sağlamak olduğundan nüfus kriterinin en önemli kriter çıkması önemlidir. Kriterlerin önem sıralaması nüfus, erişilebilirlik, çevredeki okul sayısı, güvenlik, çevre kirliliği, potansiyel büyüme ve altyapı şeklindedir. Alternatiflerin siralandığı TOPSIS yönteminin sonuçlarına bakıldığında okul kurulması için en uygun yerin $\left(A_{16}\right) 16$. yer olduğu gözlenmektedir.

İleriki çalışmalarda, sözel ifadelerdeki belirsizliğin probleme daha iyi yansıtılması amacıyla çalışmaya bulanık AHP ve bulanık TOPSIS yöntemleri uygulanabilir. Karar vericilerden bir grup oluşturularak farklı görüşlerin çalışmaya yansıtılması sağlanabilir. Ayrıca, yürüme mesafesinin dişında en uzak mesafenin en küçüklenmesi gibi farklı amaçların gözetildiği çözüm yaklaşımları ele alınabilir.

\section{KAYNAKLAR (REFERENCES)}

[1] Burrough P.A., "Principles of geographical information systems, Oxford University Press, Newyork, (1998).

[2] ReVelle C.S. and Eiselt H.A., "Location analysis: a synthesis and survey, European Journal of Operational Research, 165(1): 1-19, (2005).

[3] Narula S.C., 1Minisum hierarchical location-allocation problems on a network: A survey", Annals of Operations Research, 6(8): 255-272 (1986).

[4] Daskin M.S., " Network and discrete locations: models, algorithms and applications", Wiley and Sons, New York, (1995).

[5] Owen S.H. and Daskin, M.S., "Strategic facility location: A review", European Journal of Operational Research, 111 (3): 423-447, (1998).

[6] Arabani A.B. and Farahani R.Z., "Facility location dynamics: An overview of classifications and applications", Computers \& Industrial Engineering, 62 (1): 408-420 (2012).

[7] Önüt S. and Soner S., "Transshipment site selection using the AHP and TOPSIS approaches under fuzzy environment, Waste Management, 28(9): 1552-1559, (2008).

[8] Vahidnia M.H., Alesheikh A.A. and Alimohammadi A., "Hospital site selection using fuzzy AHP and its derivatives", Journal of Environmental Management, 90(10): 3048-3056, (2009).

[9] Lai W., Han-Lun L., Qi,L., Jing-Yi,C. and Yi-Jiao C., "Study and implementation of fire sites planning based on GIS and AHP", Procedia Engineering, 11: 486-495, (2011).

[10] Roig-Tierno N., Baviera-Puig A., Buitrago-Vera J. and Mas-Verdu F., "The retail site location decision process using GIS and the analytical hierarchy process, Applied Geography, 40: 191-198, (2013).

[11] Uyan, M., "GIS-based solar farms site selection using analytic hierarchy process (AHP) in Karapinar region, Konya/Turkey," Renewable and Sustainable Energy Reviews, 28: 11-17,(2013).

[12] Sánchez-Lozano J.M., Teruel-Solano J., Soto-Elvira P.L. and García-Cascales M.S., "geographical information systems (GIS) and multi-criteria decision making (MCDM) methods for the evaluation of solar farms locations: Case study in south-eastern Spain", Renewable and Sustainable Energy Reviews, 24: 544556, (2013).

[13] Mishra A.K., Deep S. and Choudhary A., "Identification of suitable sites for organic farming using AHP \& GIS", The Egyptian Journal of Remote Sensing and Space Science, 18(2): 181-193, (2015).

[14] Rasli F.N., Kanniah K.D., Muthuveerappan C. and Ho C.S, "An integrated approach of analytical hierarchy process and GIS for site selection of urban parks in Iskandar Malaysia”, International Journal of Geoinformatics, 12(2): 67-77, (2016).

[15] Çetinkaya C., Özceylan E., Erbaş M. and Kabak M., “ GIS-based fuzzy MCDA approach for siting refugee camp: A case study for southeastern Turkey", 
International Journal of Disaster Risk Reduction, 18: 218-231, (2016).

[16] Chaudhary P., Chhetri S.K., Joshi K.M., Shrestha B.M. and Kayastha P., "Application of an Analytic Hierarchy Process (AHP) in the GIS interface for suitable fire site selection: A case study from Kathmandu Metropolitan City,Nepal", Socio-Economic Planning Sciences, 53: 60-71, (2016).

[17] McNamara J.F., "Mathematical Programming Models in Educational Planning", Review of Educational Research, 41(5) :419-446, (1971).

[18] Bruno J.E. and Andersen P.W. Analytical methods for planning educational facilities in an era of declining enrollments", Socio-Economic Plan. Sci., 16(3): 121131, (1982).

[19] Kavili Arap S., "Türkiye'de üniversitelere ilișkin politikalar ve üniversitelerin kuruluş yeri seçimi", Doktora Tezi, İnönü Üniversitesi Sosyal Bilimler Enstitüsü, (2007).

[20] Özdemir B. and Tokyay O., "Multi criteria decision support for the best allocation of the primary school area. International Multidisciplinary Scientific GeoConference: SGEM: Surveying Geology \& mining Ecology Management, 1: 457, (2013).

[21] Arslan H.M. ve Yıldız M.S., "Eğitim tesislerinin kuruluş yeri seçiminde bulanık TOPSIS yönteminin uygulanması: Düzce'de bir lokasyon analizi, "The Journal of International Social Research, 8(36) : 763-774, (2015).
[22] İnternet: URL: http://mevzuat.meb.gov.tr/html/24.html, Meb mevzuat, İlköğretim ve Eğitim Kanunu, 7. Bölüm, 61.madde, (Son erişim tarihi: 11.07.2016).

[23] Saaty T.L., "The analytic hierarchy process", New York: McGraw-Hill, (1980).

[24] Saaty T.L., " Decision making with the analytic hierarchy process, "International Journal of Services Sciences, 1(1): 83-98, (2008).

[25] Arıbaş M. ve Özcan U., "Akademik araştırma projelerinin AHP ve TOPSIS yöntemleri kullanılarak değerlendirilmesi, Politeknik Dergisi, 19(2): 163-173, (2016).

[26] Saaty T.L., "How to make a decision: the analytic hierarchy process," European Journal of Operational Research, 48: 9-26, (1990).

[27] Supçiller A.A. ve Çapraz O., "AHP-TOPSIS yöntemine dayalı tedarikçi seçimi uygulaması", Ekonometri ve Istatistik, 13: 1-22, (2011).

[28] Monjezi M., Dehghani H., Singh T.N., Sayadi A.R. and Gholinejad A., "Application of TOPSIS method for selecting the most appropriate blast design", Arabian Journal of Geosciences, 5(1): 95-101, (2010).

[29] İnternet: URL: http://www.cankaya.bel.tr/pages/14/ RAKAMLARLA-CANKAYA (Son erișim tarihi: 05.08.2016). 